\title{
Athletes Abstinence Knowledgefrom Eating Disorders like Anorexia Nervosa (AN), Bulimia Nervosa (BN) and Binge Eating Disorder (BED), as Health Education Method in Decreasing Unhealthy Ageing with Reference to Physical and Mental Health
}

\author{
Bebeley Samuel Joseph, LaggaoSam Augustine and Tucker Henry Joe
}

\begin{abstract}
Aim: The objective of this study was to point out abstinence knowledge in decreasing unhealthy ageing with reference to physical and mental health, with justification to evaluate athlete's abstinence knowledge from eating disorders like Anorexia Nervosa (AN), Bulimia Nervosa $(\mathrm{BN})$ and Binge Eating Disorder (BED) as health education method in decreasing unhealthy ageing with reference to physical and mental health among athletes at Njala Campus.

Method: Behavioral Health Risk Modified Survey Questionnaire (BHRMSQ) was the research instrument for the survey. The variables of the findings were proved at level of significance $p<0.05$ through an inferential statistical instrument called Dependent t-test ( $t$ ). The researchers interviewed mainly undergraduate athletes with an average number of one hundred and fifty $(n=150)$, of which $37 \%(n=55)$ female and $63 \%(n=95)$ male, were selected using the stratified random sampling. Also stratified were $43.2 \%(n=65)$ from the School of Agriculture-to-Environmental Science; $57 \%(n=85)$ from the School of Education-to-Technology; $83 \%(n=125)$ from level $(100$-to-200); 17\% $(n=25)$ from level (300-to-400); $60 \%(n=90)$ within the age circle of $(18$-to-25); $40 \%(n=60)$ within the age circle of (26-to-30+) in years. Results: Analysis shows negative skewedness in all three variables as placed in tabulated values (t-scores of $0.237,0.452$ and 0.318 ) of 5,7 and 9 when proved at $\mathrm{p}<0.05$. Conclusion: The findings demonstrated that majority of athletes' lack abstinence knowledge from eating disorders like Anorexia Nervosa (AN), Bulimia Nervosa (BN) and Binge Eating Disorder (BED) regarding health education method in decreasing unhealthy ageing with reference to physical and mental health among athletes at Njala Campus.
\end{abstract}

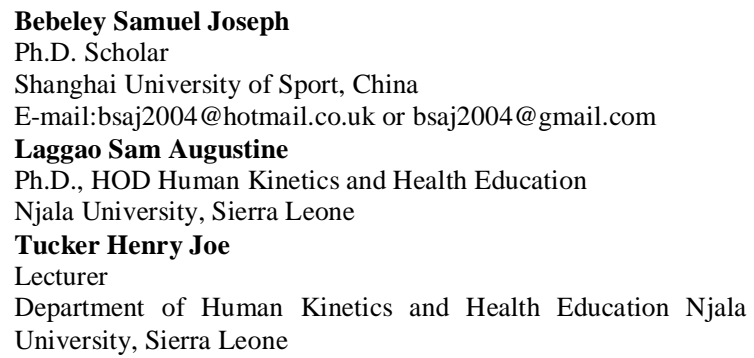

Key Words: Anorexia Nervosa, Binge Eating Disorder, Bulimia Nervosa, Health Education, Physical Fitness

DOI: $10.18376 / j e s p / 2017 / v 13 / i 1 / 111268$

\section{Introduction}

Health Education is a profession of educating people about health, McKenzie, J. et al. (2009), which encompass environmental health, physical health, social health, emotional health, intellectual health, and spiritual health, Donatelle, $R$. (2009). It can be defined as the principle by which individuals and groups of people learn to behave in a manner conducive to the promotion, maintenance, or restoration of health, Donatelle, R. (2009). However, Health Education can also be defined as any combination of planned learning experiences based on sound theories that provide 


\section{Journal of Exercise Science \& Physiotherapy, Vol. 13, No. 1, 2017 \\ ISSN: 0973-2020 (Print) I2OR Impact Factor $=5.23$ UGC Approved [no.20489] ISSN: 2454-6089 \\ (Online)}

individuals, groups, and communities the opportunity to acquire information and the skills needed to make quality health decisions, Joint Committee on Terminology (2001). The World Health Organization defined Health Education as comprising of consciously constructed opportunities for learning involving some form of communication designed to improve health literacy, including improving knowledge, and developing life skills which are conducive to individual and community health, World Health Organization (1998). It is perhaps a common perception that collegiate athletes are automatically healthier and more attentive to their overall wellbeing. Indeed, Nattiv and Puffer in "Lifestyles and Health Risks of Collegiate Athletes," suggested that college athletes appear to be at a higher risk for certain lifestyle behaviours. The added emotional, physical, and mental stress from athletics may result in certain maladaptive behaviours in athletes. Nattiv, A. et al. (1991).

Eating Disorders are mental illnesses defined by abnormal eating habits that negatively affect a person's physical or mental health, American Psychiatry Association (2013). They include binge eating disorder where people eat a large amount in a short period of time, anorexia nervosa where people eat very little and thus have a low body weight, bulimia nervosa where people eat a lot and then try to rid themselves of the food, pica where people eat non-food items, rumination disorder where people regurgitate food, avoidant/restrictive food intake disorder where people have a lack of interest in food, and a group of other specified feeding or eating disorders, American Psychiatry Association (2013). Anxiety disorders, depression, and substance abuse are common among people with eating disorders. These disorders do not include obesity, American Psychiatry Association (2013). The cause of eating disorders is not clear. Both genetic and environmental factors appear to play a role, Rikani, A. A. et al. (2013).

The term Anorexia Nervosa (AN) was coined in 1873 by Sir William Gull; one of Queen Victoria's personal physicians, Gull, W. W. (1997). The history of anorexia nervosa begins with descriptions of religious fasting dating from the Hellenistic era, Pearce, J. M. (2004), and continuing into the medieval period. The medieval practice of self-starvation by women, including some young women, in the name of religious piety and purity also concerns anorexia nervosa; it is sometimes referred to as anorexia mirabilis, EspiForcen, F. (2013). The earliest medical descriptions of anorexic illnesses are generally credited to English physician Richard Morton in 1689, Pearce, J. $M$. (2004). In the late 19th century anorexia nervosa became widely accepted by the medical profession as a recognized condition. In 1873, Sir William Gull, one of Queen Victoria's personal physicians, published a seminal paper, which coined the term anorexia nervosa and provided a number of detailed case descriptions and treatments, Gull, Sir William Withey (1894). Anorexia nervosa, often referred to simply as anorexia, Sari Fine Shepphird (2009) is an eating disorder characterized by a low weight, fear of gaining weight, a strong desire to be thin, and food restriction, What are Eating Disorders?NIMH: (2015). Anorexia nervosa is an eating disorder that is characterized by attempts to lose weight, to the point of starvation, Surgenor, L. J. et al. (2013). Many people with anorexia see themselves as overweight even though they are underweight, Attia, E. (2010). If asked they usually deny they have a problem with low weight, American Psychiatric Publishing, (2013). Often they weigh themselves frequently, eat only small amounts, and only eat certain foods. Some will exercise excessively, force themselves to vomit, or use laxatives to produce weight loss. Complications may include osteoporosis, infertility, and heart damage among others, What are Eating Disorders?NIMH: (2015). Women will often stop having menstrual periods, American Psychiatric Publishing, (2013). Anorexia often begins following a major life change or stress-inducing event. The diagnosis requires a significantly low weight. The severity of disease is based on body mass index (BMI) in adults with mild disease having a BMI of greater than 17, moderate a BMI of 16 to 17 , severe a BMI of 15 to 16 , and extreme a BMI less than 15 


\section{Journal of Exercise Science \& Physiotherapy, Vol. 13, No. 1, 2017 \\ ISSN: 0973-2020 (Print) I2OR Impact Factor $=5.23$ UGC Approved [no.20489] ISSN: 2454-6089 \\ (Online)}

American Psychiatric Publishing, (2013). Anorexia nervosa has been increasingly diagnosed since 1950, Eating disorders and culture (2004), the increase has been linked to vulnerability and internalization of body ideals, Herpertz-Dahlmann B, et al. (2013). People in professions where there is a particular social pressure to be thin (such as models and dancers) were more likely to develop anorexia, Herpertz-Dahlmann B, et al. (2013) and those with anorexia have much higher contact with cultural sources that promote weight loss, Herpertz-Dahlmann B, et al. (2013). This trend can also be observed for people who partake in certain sports, such as jockeys and wrestlers, Eileen P. et al. (2004). There is a higher incidence and prevalence of anorexia nervosa in sports with an emphasis on aesthetics, where low body fat is advantageous, and sports in which one has to make weight for competition, Baum, A. (2006).

The term Bulimia Nervosa (BN) means disease of hunger affecting the nervous system, Douglas Harper (2001).Bulimia nervosa, also known as simply bulimia, is an eating disorder characterized by binge eating followed by purging. Binge eating refers to eating a large amount of food in a short amount of time. Purging refers to attempts to rid oneself of the food consumed. This may be done by vomiting or taking a laxative, Bulimia nervosa fact sheet (2012). Other efforts to lose weight may include the use of diuretics, stimulants, fasting, or excessive exercise, Hay, P. J. et al. (2010). Most people with bulimia have a normal weight, Bulik, C. M. et al. (2012). Bulimia is frequently associated with other mental disorders such as depression, anxiety, and problems with drugs or alcohol, Bulimia nervosa fact sheet (2012). There is also a higher risk of suicide and self-harm, Smink, F. R. et al. (2012). Bulimia is more common among those who have a close relative with the condition, Bulimia nervosa fact sheet (2012). The percentage risk that is estimated to be due to genetics is between $30 \%$ and $80 \%$, Hay, P. J. et al. (2010). Other risk factors for the disease include psychological stress, cultural pressure for a certain body type, poor self-esteem, and obesity, Hay, $P$. J. et al. (2010). Living in a culture that promotes dieting and having parents that worry about weight are also risks, Hay, P. J. et al. (2010). There are higher rates of eating disorders in groups involved in activities, which idealize a slim physique, such as dance, Tölgyes T. et al. (2004), gymnastics, modeling, cheerleading, running, acting, swimming, diving, rowing and figure skating. Bulimia is thought to be more prevalent among Caucasians, Franko, D. L. et al. (2007), however, a study showed that African-American teenage girls were 50 percent more likely than white girls to exhibit bulimic behaviour, including both binging and purging, McBride, H. (2012). Bulimia is about nine times more likely to occur in women than men. Among women, rates are highest in young adults, American Psychiatric Association (2013). Bulimia nervosa can be difficult to detect, compared to anorexia nervosa, because bulimics tend to be of average or slightly above or below average weight. Many bulimics may also engage in significantly disordered eating and exercising patterns without meeting the full diagnostic criteria for bulimia nervosa, Walsh, J. et al. (2000). Although diagnostic criteria for bulimia nervosa did not appear until 1979, evidence suggests that binging and purging were popular in certain ancient cultures. The first documented account of behaviour resembling bulimia nervosa was recorded in Xenophon's Anabasis around 370 B.C, in which Greek soldiers purged themselves in the mountains of Asia Minor. It is unclear whether this purging was preceded by binging, Giannini, A. J. (1993). In ancient Egypt, physicians recommended purging once a month for three days in order to preserve health, Russell, G. (1997). This practice stemmed from the belief that human diseases were caused by food itself. In ancient Rome, elite society members would vomit in order to "make room" in their stomachs for more food at all day banquets, Russell, G. (1997).

Binge Eating Disorder (BED) is characterized by binge eating without subsequent purging episodes. The disorder was first described in 1959 by psychiatrist and researcher Albert Stunkard as "night eating syndrome" (NES), and the term "binge eating" was coined to describe the same 


\section{Journal of Exercise Science \& Physiotherapy, Vol. 13, No. 1, 2017 \\ ISSN: 0973-2020 (Print) $\quad$ I $_{2}$ OR Impact Factor $=5.23 \quad$ UGC Approved [no.20489] ISSN: 2454-6089 \\ (Online)}

binging-type eating behaviour without the exclusive nocturnal component, Brewerton, T. (2014). Binge eating is one of the most prevalent eating disorders among adults, Saguy, A. et al. (2014), though there tends to be less media coverage and research about the disorder in comparison to anorexia nervosa and bulimia nervosa. Binge eating is a core symptom of binge eating disorder; however, not everyone who binge eats has binge eating disorder, Fairburn, C. (2013). An individual may occasionally binge eat without experiencing many of the negative physical, psychological, or social effects of binge eating disorder. This example may be considered an eating problem (or not), rather than a disorder, Fairburn, $C$. (2013). People with binge eating disorder can seek help from health professionals including physicians, nutritionists, psychiatrists, psychologists or clinical social workers. Even those who are not overweight are usually upset by their binge eating, and treatment can help them. Cognitive behavioural therapy (CBT) treatment has been demonstrated as a more effective form of treatment for BED than behavioural weight loss programs with 50 percent of BED individuals achieving complete remission from binge eating, Westerburg, D. P. et al. (2013). Although mental health professionals may be attuned to the signs of binge eating disorders, many physicians do not raise the question, often because they are uninformed about the specifics of the condition. Until 2013, binge eating disorder was categorized as an Eating Disorder-Not Otherwise Specified-an umbrella category for eating disorders that don't fall under the categories for anorexia nervosa or bulimia nervosa, Iacovino, J. M. et al. (2012). Binge eating disorder is the most common eating disorder in adults, Iacovino, J. M. et al. (2012), though there is generally less research on binge eating disorder in comparison to anorexia nervosa and bulimia nervosa, Saguy, A. et al. (2014), The lifetime prevalence of binge eating disorder has been observed in studies to be 2.0 percent for men and 3.5 percent for women, higher than that of the commonly recognized eating disorders anorexia nervosa and bulimia nervosa, Westerburg, D. P. et al. (2013). Additionally, 30 to 40 percent of individuals seeking treatment for weight-loss can be diagnosed with binge eating disorder, Westerburg, D. P. et al. (2013).

Athletes that are engaged in educationally sponsored institutional organized games and sports competitions are called collegiate athletes, Gerdy, R. (2000). According to Muffuli, et al. (2003), athletes that exhibit in their behavioural characteristics that which portrays abstinence from the negativities posed by behavioural risk factors of unhealthy ageing in line with physical and mental health is characterized as primary method of preventive knowledge. Ageing therefore, is referred to physical, mental and social wellbeing in older age which is often associated with degenerative processes, including reduction in musculoskeletal strength, prolonged reaction times, difficulty in respiration, increased obesity and decreased anaerobic capacity and aerobic fitness among others, Austad, et al.(2000).

This study was objected to point out abstinence knowledge of athletes at Njala Campus in decreasing unhealthy ageing with reference to physical and mental health from Anorexia Nervosa (AN), Bulimia Nervosa (BN) and Binge Eating Disorder (BED) as eating disorders in rank and file of level 100-to-200 and level 300-to-400, and to justify comparatively the significant difference if any between the dependent variables of "Yes and No" feedback regarding Anorexia Nervosa (AN), Bulimia Nervosa (BN) and Binge Eating Disorder (BED).

\section{Materials and Methods}

The researcher conducted an interview mainly on undergraduate athletes with an average number of one hundred and fifty $(n=150)$, of which $37 \%(n=55)$ female and $63 \%(n=95)$ male; $47 \%(n=70)$ Christians; 53.2\% ( $\mathrm{n}=80)$ Muslims; 7\% ( $\mathrm{n}=10)$ married; 93\% $(\mathrm{n}=140)$ single; 66.6\% $(\mathrm{n}=100)$ from South-East; $33 \%(n=50)$ from North-West, were selected using the stratified random sampling. Also stratified were 43.2\% $(\mathrm{n}=65)$ from the School of Agriculture-to-Environmental Science; 57\% $(n=85)$ from the School of Education-to-Technology; $83 \%(n=125)$ from level (100-to-200); 17\% 
$(\mathrm{n}=25)$ from level (300-to-400); $60 \%(\mathrm{n}=90)$ within the age circle of (18-to-25); 40\% ( $\mathrm{n}=60)$ within the age circle of (26-to-30+) in years.

The survey research design was used for this study with dependent variables of Anorexia Nervosa (AN), Bulimia Nervosa (BN) and Binge Eating Disorder (BED). The behavioural health risk modified survey questionnaire (BHRMSQ) was enforced as research tool for proving the objective, which was formally enforced by Bebeley, et al. (2016). The questionnaire instrument was classed under demographic data and variable data. Research Professionals from Njala University and Shanghai University of Sport, cross-examined and validated the questionnaire as a viable research instrument with a pre-test on 50 Athletes from Kenema Polytech as tabulated in 1, 2and 3.

The researchers interviewed mainly undergraduate athletes with an average number of one hundred and fifty $(n=150)$ in rank and file of level 100-to-200 and level 300-to-400 ranging from the School of Agriculture-to-Environmental Science and Education-to-Technology, from Njala Campus, helped by some academic staff colleagues of the Department of Human Kinetics and Health Education, were able to grant face-to-face interview with the respondents focusing on the dependent variables. The interview meeting took place at the Sport Complex. The individual responses were compiled for statistical analyses. The inferential statistics of Dependent $t$-test $(t)$ among others, were enforced during the analyses of the dependent data of "Yes and No" obtained from "Anorexia Nervosa (AN), Bulimia Nervosa (BN) and Binge Eating Disorder (BED)" regarding abstinence knowledge of athletes in decreasing unhealthy ageing with reference to physical and mental health using a behavioural health risk modified survey questionnaire (BHRMSQ) as research tool for proving the objective, which was formally enforced by Bebeley, et al. (2016). The results were proved@ level of significance $\mathrm{p}<0.05$.

\section{Results}

Table 1. Test-Retest of Polytech Athletes abstinence knowledge of Anorexia Nervosa

\begin{tabular}{|c|c|c|c|c|c|c|c|c|c|c|c|c|}
\hline \multirow{3}{*}{ 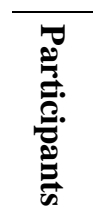 } & \multicolumn{4}{|c|}{$\begin{array}{c}\text { Anorexia Nervosa } \\
\quad(n=50)\end{array}$} & \multicolumn{2}{|c|}{$\mathbf{R}^{2}$} & \multicolumn{2}{|c|}{$\mathbf{S}^{2}$} & \multicolumn{2}{|c|}{ Ti } & \multicolumn{2}{|c|}{$\mathbf{T i}^{2}$} \\
\hline & \multicolumn{2}{|c|}{$\begin{array}{c}\mathbf{R} \\
(\text { Yes })\end{array}$} & \multicolumn{2}{|c|}{$\begin{array}{c}\mathrm{S} \\
(\mathrm{No})\end{array}$} & \multirow[t]{2}{*}{$\mathbf{I}_{1}$} & \multirow[t]{2}{*}{$\mathbf{I}_{2}$} & \multirow[t]{2}{*}{$\mathbf{I}_{1}$} & \multirow[t]{2}{*}{$\mathbf{I}_{2}$} & \multicolumn{2}{|c|}{$\begin{array}{c}\text { Sum } \\
\left(\mathbf{I}_{1}+\mathbf{I}_{2}\right)\end{array}$} & \multicolumn{2}{|c|}{$\begin{array}{ll}\text { Sum } \\
\left.+I_{2}\right)\end{array}$} \\
\hline & $\mathbf{I}_{1}$ & $\mathbf{I}_{2}$ & $\mathbf{I}_{1}$ & $\mathbf{I}_{2}$ & & & & & $\mathbf{R}$ & $\mathbf{S}$ & $\mathbf{R}$ & $\mathbf{S}$ \\
\hline 1 & 48 & 47 & 02 & 03 & 2304 & 2209 & 04 & 09 & 95 & 05 & 9025 & 25 \\
\hline 2 & 41 & 40 & 09 & 10 & 1681 & 1600 & 81 & 100 & 81 & 19 & 6561 & 361 \\
\hline 3 & 46 & 45 & 04 & 05 & 2116 & 2025 & 16 & 25 & 91 & 09 & 8281 & 81 \\
\hline 4 & 43 & 42 & 07 & 08 & 1849 & 1764 & 49 & 64 & 85 & 15 & 7225 & 225 \\
\hline 5 & 35 & 34 & 15 & 16 & 1225 & 1156 & 225 & 256 & 69 & 31 & 4761 & 961 \\
\hline 6 & 38 & 37 & 12 & 13 & 1444 & 1369 & 144 & 169 & 75 & 25 & 5625 & 625 \\
\hline$\overline{(n=6)}$ & \multicolumn{2}{|c|}{$\sum R=496$} & \multicolumn{2}{|c|}{$\sum S=104$} & $\sum \mathbf{R}^{2}$ & 20742 & \multicolumn{2}{|c|}{$\sum S^{2}=1142$} & \multicolumn{2}{|c|}{$\sum \mathbf{T i}^{2}=$} & 41478 & 2278 \\
\hline & \multicolumn{2}{|c|}{$\begin{array}{l}\left(\sum R\right)^{2}= \\
246016\end{array}$} & \multicolumn{2}{|c|}{$\left(\sum S\right)^{2}=10816$} & \multicolumn{8}{|c|}{$*$ ICCR $=0.99$} \\
\hline
\end{tabular}

Table 2. Test-retest of Polytech Athletes abstinence knowledge of Bulimia Nervosa

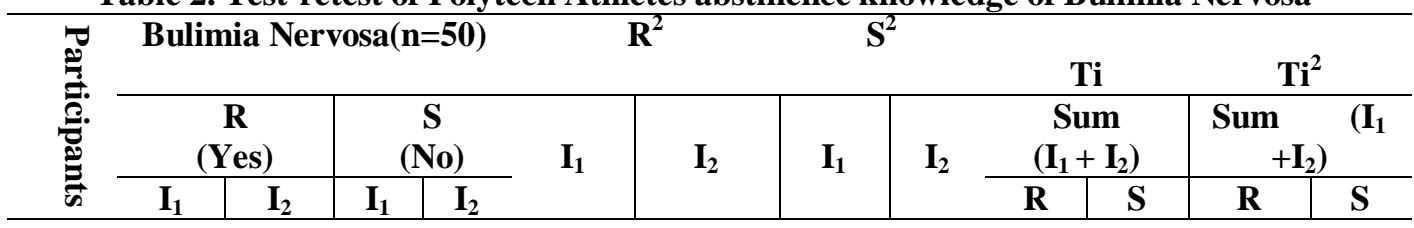


Journal of Exercise Science \& Physiotherapy, Vol. 13, No. 1, 2017

ISSN: 0973-2020 (Print) I I OR Impact Factor $=5.23$ UGC Approved [no.20489]

(Online)

\begin{tabular}{|c|c|c|c|c|c|c|c|c|c|c|c|c|}
\hline 1 & 48 & 47 & 02 & 03 & 2304 & 2209 & 04 & 09 & 95 & 05 & 9025 & 25 \\
\hline 2 & 44 & 43 & 06 & 07 & 1936 & 1849 & 36 & 49 & 87 & 13 & 7569 & 169 \\
\hline 3 & 38 & 37 & 12 & 13 & 1444 & 1369 & 144 & 169 & 75 & 25 & 5625 & 625 \\
\hline 4 & 40 & 39 & 10 & 11 & 1600 & 1521 & 100 & 121 & 79 & 21 & 6241 & 441 \\
\hline 5 & 37 & 36 & 13 & 14 & 1369 & 1296 & 169 & 196 & 73 & 27 & 5329 & 729 \\
\hline 6 & 34 & 33 & 16 & 17 & 1156 & 1089 & 256 & 289 & 67 & 33 & 4489 & 1089 \\
\hline \multirow[b]{2}{*}{$(n=6)$} & \multicolumn{2}{|c|}{$\sum R=476$} & \multicolumn{2}{|c|}{$\sum S=124$} & $\sum \mathbf{R}^{2}$ & 19142 & \multicolumn{2}{|c|}{$\sum S^{2}=1542$} & \multicolumn{2}{|c|}{$\sum \mathbf{T i}^{2}=$} & 38278 & 3078 \\
\hline & \multicolumn{2}{|c|}{$\begin{array}{l}\left(\sum \mathbf{R}\right)^{2}= \\
226576\end{array}$} & \multicolumn{2}{|c|}{$\begin{array}{c}\left(\sum S\right)^{2}= \\
15376\end{array}$} & \multicolumn{8}{|c|}{$*$ ICCR $=0.99$} \\
\hline
\end{tabular}

Table 3. Test-Retest of Polytech Athletes abstinence knowledge of Binge Eating Disorder

\begin{tabular}{|c|c|c|c|c|c|c|c|c|c|c|c|c|}
\hline \multirow{3}{*}{ 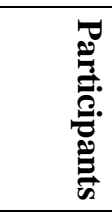 } & \multicolumn{4}{|c|}{$\begin{array}{l}\text { Binge Eating Disorder } \\
(\mathbf{n}=50)\end{array}$} & \multicolumn{2}{|c|}{$\mathbf{R}^{2}$} & \multicolumn{2}{|c|}{$\mathbf{S}^{2}$} & \multicolumn{2}{|c|}{$\mathbf{T i}$} & \multicolumn{2}{|c|}{$\mathbf{T i}^{2}$} \\
\hline & \multicolumn{2}{|c|}{$\begin{array}{c}\mathbf{R} \\
(\mathbf{Y e s})\end{array}$} & \multicolumn{2}{|c|}{$\begin{array}{c}\mathbf{S} \\
\text { (No) }\end{array}$} & \multirow[t]{2}{*}{$\mathbf{I}_{1}$} & \multirow[t]{2}{*}{$\mathbf{I}_{2}$} & \multirow[t]{2}{*}{$\mathbf{I}_{1}$} & \multirow[t]{2}{*}{$\mathbf{I}_{2}$} & \multicolumn{2}{|c|}{$\begin{array}{c}\text { Sum } \\
\left(\mathbf{I}_{1}+\mathbf{I}_{2}\right)\end{array}$} & \multicolumn{2}{|c|}{$\operatorname{Sum}_{\left.+\mathbf{I}_{2}\right)}\left(\mathbf{I}_{1}\right.$} \\
\hline & $I_{1}$ & $\mathbf{I}_{2}$ & $I_{1}$ & $\mathbf{I}_{2}$ & & & & & $\mathbf{R}$ & $\mathbf{S}$ & $\mathbf{R}$ & $\mathbf{S}$ \\
\hline 1 & 47 & 46 & 03 & 04 & 2209 & 2116 & 09 & 16 & 93 & 07 & 8649 & 49 \\
\hline 2 & 42 & 41 & 08 & 09 & 1764 & 1681 & 64 & 81 & 83 & 17 & 6889 & 289 \\
\hline 3 & 36 & 35 & 14 & 15 & 1296 & 1225 & 196 & 225 & 71 & 29 & 5041 & 841 \\
\hline 4 & 45 & 44 & 05 & 06 & 2025 & 1936 & 25 & 36 & 89 & 11 & 7921 & 121 \\
\hline 5 & 34 & 33 & 16 & 17 & 1156 & 1089 & 256 & 289 & 67 & 33 & 4489 & 1089 \\
\hline 6 & 30 & 29 & 20 & 21 & 900 & 841 & 400 & 441 & 59 & 41 & 3481 & 1681 \\
\hline & $\sum \mathbf{R}$ & 462 & & 138 & $\sum \mathbf{R}^{2}$ & 18238 & $\sum \mathbf{S}^{2}=$ & 2038 & & & 36470 & 4070 \\
\hline$(n=6)$ & & & $\left(\sum \mathbf{S}\right)^{2}$ & & & & & $\overline{C C R}$ & 0.99 & & & \\
\hline
\end{tabular}

Table 4. Abstinence Knowledge of Njala Campus Athletes from Anorexia_Nervosa $(\mathbf{n}=150)$ Dependent Variable-One Anorexia Nervosa

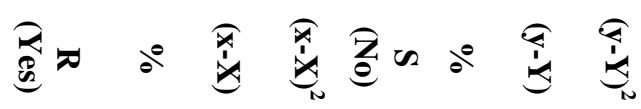

1 Do you know that Anorexia Nervosa as one of the health risk factors can be linked to Hypo-kalaemia (a drop in the level of potassium in the blood), which can cause abnormal heart rhythms, constipation, fatigue, muscle damage

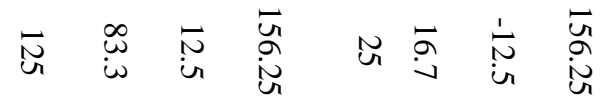
and paralysis?

2 Do you know that prolonged weight loss as a result of refusal to maintain once normal body mass index (NBMI) for one's age can be linked to Anorexia Nervosa, which can cause amenorrhea (abnormal absence of menstruation),

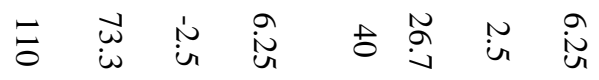
brittle hair, and skin to become yellow and unhealthy? 
3 Do you know that food rituals (such as cutting food into tiny pieces, refusing to eat around others, hiding or discarding food), purging (the use of laxatives, diet pills, ipecac syrup, or water pills) and self-induced vomiting (running to the bathroom after eating in

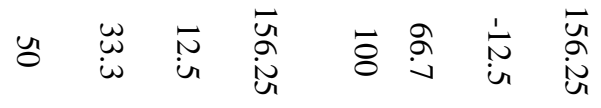
order to vomit and quickly get rid of ingested calories) can lead to Anorexia Nervosa?

4 Do you know that Anorexia Nervosa can lead to growth retardation (height gain may slow and can stop completely with severe weight loss or chronic

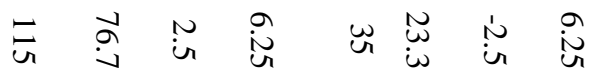
malnutrition)?

5 Do you know that Anorexia Nervosa can lead to Neurological disorders (such as seizures and tremors)?

6 Do you know that Anorexia Nervosa can lead to heart disease (such as high blood pressure) and cardiac arrhythmias (also known as cardiac dysrhythmia or irregular heartbeat)?

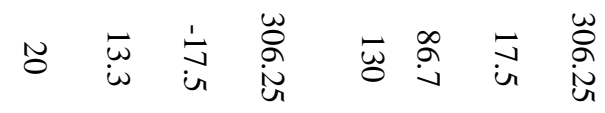

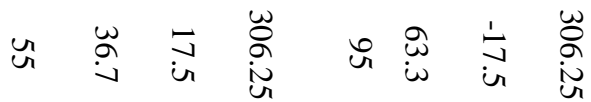

R $($ Yes $)$ [Mean \& SDev.Scores $=$

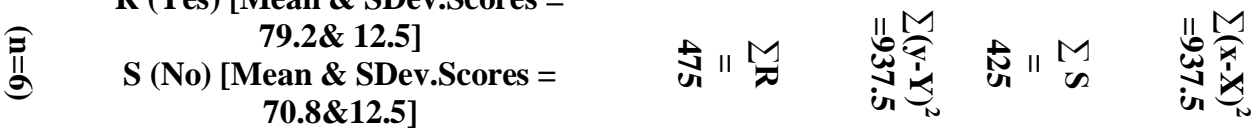

Figure 1. Abstinence Knowledge of Njala Campus Athletes from Anorexia Nervosa $(\mathrm{n}=150)$

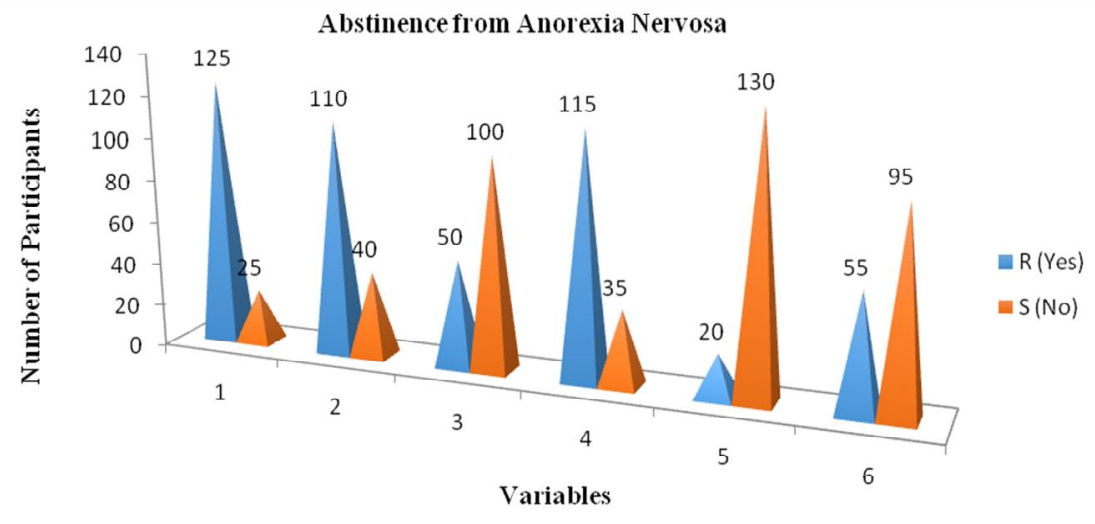


Table 5. Dependent t-test of Abstinence Knowledge of Njala Campus Athletes from Anorexia Nervosa

\begin{tabular}{|c|c|c|c|c|}
\hline \multirow[t]{2}{*}{ Participants } & \multicolumn{2}{|c|}{$\begin{array}{c}\text { Anorexia Nervosa } \\
(n=150)\end{array}$} & \multirow{2}{*}{ D } & \multirow{2}{*}{$\mathbf{D}^{2}$} \\
\hline & R (Yes) & S (No) & & \\
\hline 1 & 125 & 25 & 100 & 10000 \\
\hline 2 & 110 & 40 & 70 & 4900 \\
\hline 3 & 50 & 100 & -50 & 2500 \\
\hline 4 & 115 & 35 & 80 & 6400 \\
\hline 5 & 20 & 130 & -110 & 12100 \\
\hline 6 & 55 & 95 & -40 & 1600 \\
\hline \multirow[b]{2}{*}{$(\mathbf{n}=\mathbf{6})$} & \multirow[b]{2}{*}{$\left(\sum D\right)^{2}=2500$} & \multirow[b]{2}{*}{$* d \mathbf{d f}=5$} & $\sum \mathbf{D}=\mathbf{5 0}$ & $\sum D^{2}=37500$ \\
\hline & & & $* \mathrm{t}=\mathbf{0 . 2 3 7}$ & $* c=2.571$ \\
\hline
\end{tabular}

Table 6. Abstinence Knowledge of Njala Campus Athletes from Bulimia Nervosa $(n=150)$

IV.

\begin{tabular}{|c|c|c|c|c|c|c|c|c|}
\hline $\begin{array}{c}\text { Dependent Variable-Two } \\
\text { Bulimia Nervosa }\end{array}$ & $\underset{0}{\stackrel{R}{6}} \approx$ & $d^{9}$ & $\underset{\forall}{\ddot{y}}$ & 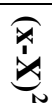 & 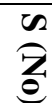 & $d^{9}$ & $\stackrel{4}{3}$ & $\stackrel{4}{3}$ \\
\hline
\end{tabular}

1 Do you know that bulimia nervosa can lead to oral trauma (in which repetitive insertion of fingers or other objects causes lacerations to the lining of the mouth or throat), esophagitis (inflammation of the esophagus) and chronic gastric reflux after eating?

2 Do you know that frequent vomiting due to bulimia nervosa causes dehydration, hypokalemia (deficiency of potassium in the bloodstream) and electrolyte imbalance, which can lead to cardiac arrhythmia, cardiac arrest, ü and even death?

3 Do you know that bulimia nervosa can lead to gastroparesis (i.e. delayed emptying), which can lead to constipation?

4 Do you know that bulimia nervosa can lead to infertility?

5 Do you know that bulimia nervosa can lead to enlarged glands in the neck, under the jaw line?

$$
\text { I } \omega_{i}
$$

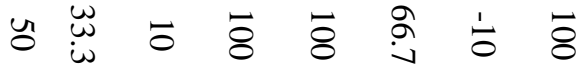

ய 융

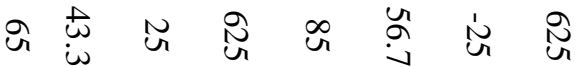

6 Do you know that bulimia nervosa can lead to physical complications such as epileptic seizures, cardiac arrhythmias and muscle weakness?

R $($ Yes) $[$ Mean \& SDev.Scores $=83.3 \&$

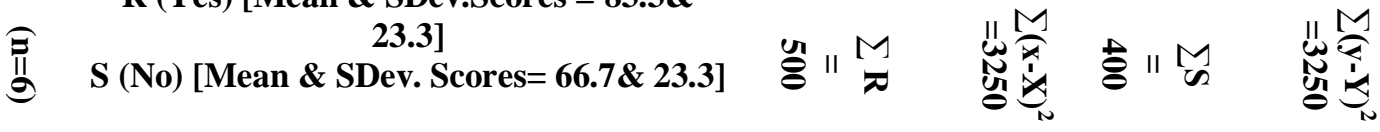




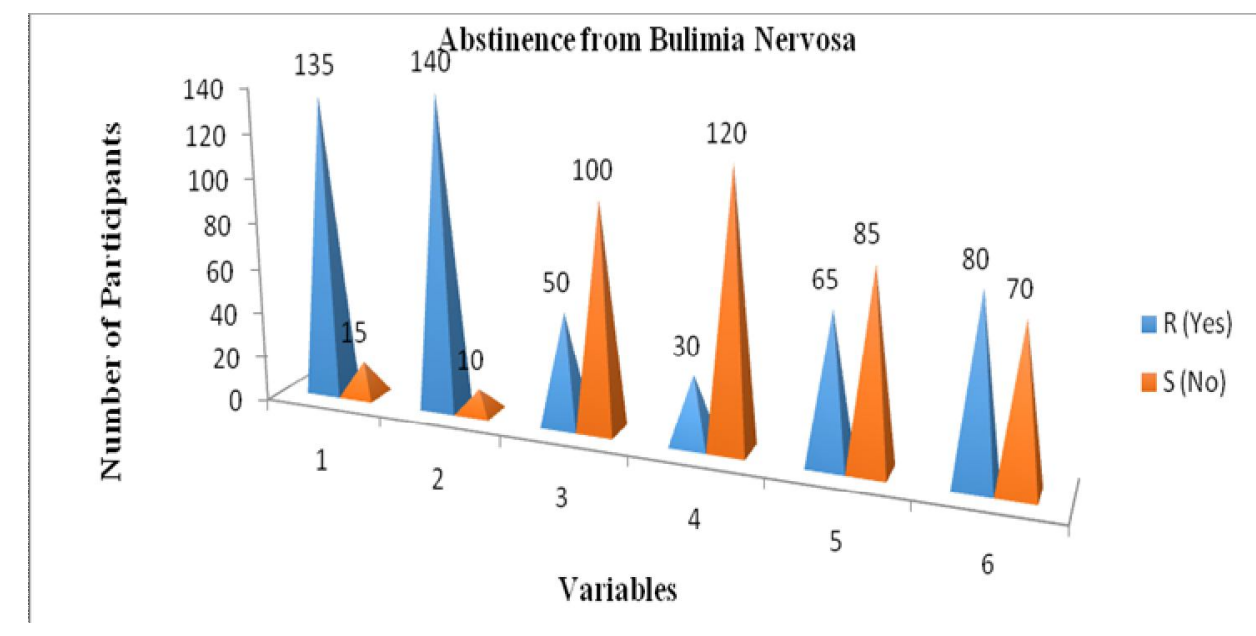

Figure 2. Abstinence Knowledge of Njala Campus Athletes from Bulimia Nervosa $(\mathbf{n = 1 5 0})$

Table 7. Dependent t-test of Abstinence Knowledge of Njala Campus Athletes from Bulimia Nervosa

\begin{tabular}{|c|c|c|c|c|}
\hline \multirow[t]{2}{*}{ Participants } & \multicolumn{2}{|c|}{$\begin{array}{c}\text { Bulimia Nervosa } \\
(\mathbf{n}=\mathbf{1 5 0})\end{array}$} & \multirow[t]{2}{*}{ D } & \multirow[t]{2}{*}{$\mathbf{D}^{2}$} \\
\hline & R (Yes) & S (No) & & \\
\hline 1 & 135 & 15 & 120 & 14400 \\
\hline 2 & 140 & 10 & 130 & 16900 \\
\hline 3 & 50 & 100 & -50 & 2500 \\
\hline 4 & 30 & 120 & -90 & 8100 \\
\hline 5 & 65 & 85 & -20 & 400 \\
\hline 6 & 80 & 70 & 10 & 100 \\
\hline & & & $\sum D=100$ & $\sum D^{2}=42400$ \\
\hline$(n=6)$ & $\left(\sum D\right)^{2}=10000$ & $* \mathbf{d f}=5$ & $* \mathrm{t}=0.452$ & $* c=2.571$ \\
\hline
\end{tabular}

Table 8. Abstinence Knowledge of Njala Campus Athletes from Binge Eating Disorder ( $n=150)$

\begin{tabular}{|c|c|c|c|c|c|c|c|c|c|}
\hline IV. & $\begin{array}{l}\text { Dependent Variable-Three } \\
\text { Binge Eating Disorder }\end{array}$ & $\underset{0}{\mathbb{R}} \approx$ & $d^{9}$ & 范 & 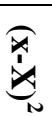 & תم & d9 & $\stackrel{4}{\xi}$ & $\underbrace{3}_{N}$ \\
\hline 1 & $\begin{array}{l}\text { Do you know that Binge Eating } \\
\text { disorder can be caused by } \\
\text { environmental factors and the } \\
\text { impact of traumatic events, which } \\
\text { may begin when an individual } \\
\text { athlete recovers from an adoption } \\
\text { of rigid eating habits? }\end{array}$ & $\vec{~}$ & $\stackrel{\infty}{\stackrel{\sim}{\sim}}$ & $\begin{array}{l}\vec{\sigma} \\
\dot{i}\end{array}$ & $\begin{array}{l}\infty \\
\infty \\
\dot{\phi}\end{array}$ & $\widetilde{N}$ & $\underset{\omega}{\omega}$ & $\begin{array}{l}\overrightarrow{0} \\
\dot{i}\end{array}$ & $\begin{array}{l}\omega \\
\infty \\
\dot{\phi} \\
+\end{array}$ \\
\hline
\end{tabular}


2 Do you know that other risk factors of Binge Eating disorder may include critical comments about weight, low self-esteem, depression, and physical or sexual abuse in childhood or early adulthood?

3 Do you know that delay in eating (e.g. not eating during the day), restriction of overall calorie intake (e.g. setting calorie limit to 1,000 calories per day) and avoidance of certain types of food (e.g. "forbidden" food, such as sugar, carbohydrates, etc.) could lead to Binge Eating disorder?

4 Do you know that individuals who have binge eating disorder commonly have other comorbidities such as major depressive disorder, personality disorder, bipolar disorder, substance abuse, body dysmorphic disorder, kleptomania, irritable bowel syndrome, fibromyalgia, or an anxiety disorder?

5 Do you know that individuals who are diagnosed with binge eating disorder exhibit neurobiological features of dysfunctional cognitive control, food addiction, and biological and environmental risk factors?

6 Do you know that persons who suffer from Binge Eating disorder have been found to have higher weight bias internalization, which includes low self-esteem, unhealthy eating patterns, and general body dissatisfaction?

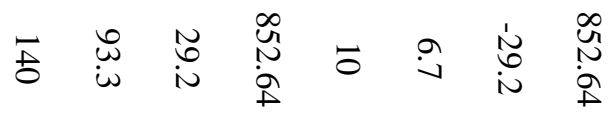

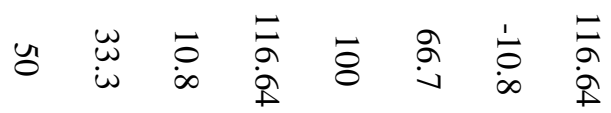

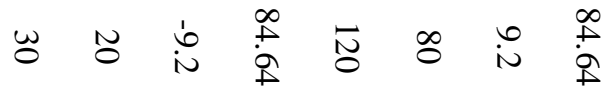

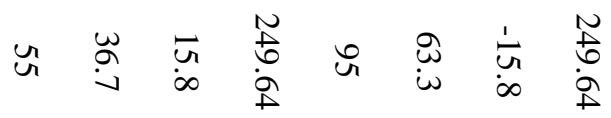

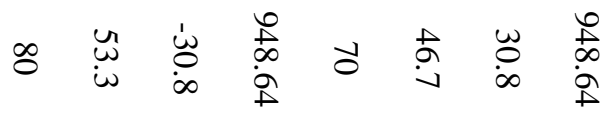
$\mathrm{R}$ (Yes) [Mean \& S Dev. Scores = $80.8 \& 20.9]$

iI $S($ No) [Mean \& S Dev. Scores = $69.2 \& 20.9]$

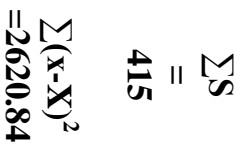


Figure 3. Abstinence Knowledge of Njala Campus Athletes from Binge Eating Disorder $(\mathbf{n}=150)$

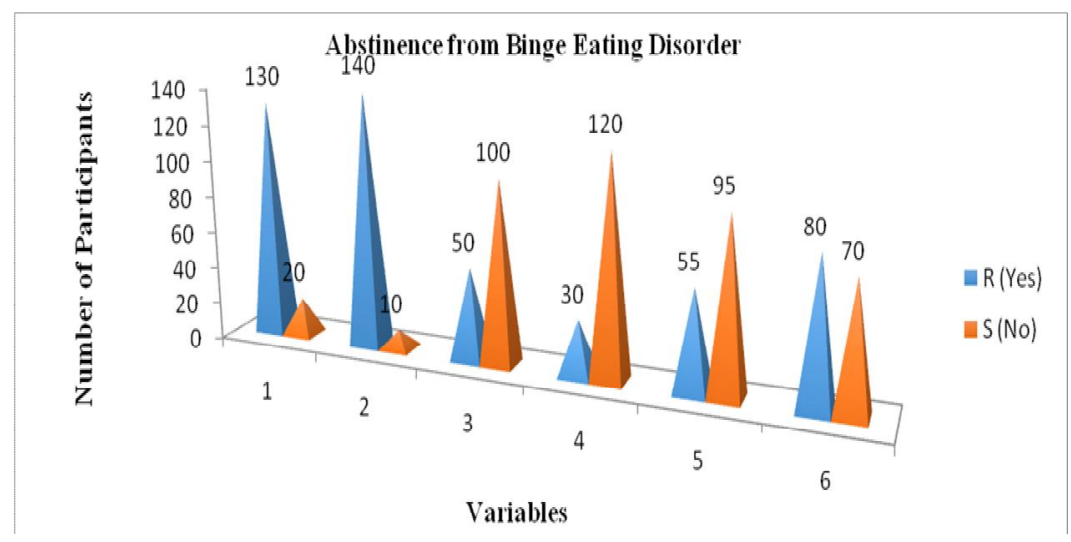

Table 9. Dependent t-test Abstinence Knowledge of Njala Athletes from Binge Eating Disorder $(\mathbf{n}=150)$

\begin{tabular}{|c|c|c|c|c|}
\hline \multirow[t]{2}{*}{ Participants } & \multicolumn{2}{|c|}{$\begin{array}{c}\text { Binge Eating Disorder } \\
(\mathrm{n}=150)\end{array}$} & \multirow[t]{2}{*}{ D } & \multirow[t]{2}{*}{$D^{2}$} \\
\hline & R (Yes) & S (No) & & \\
\hline 1 & 130 & 20 & 110 & 12100 \\
\hline 2 & 140 & 10 & 130 & 16900 \\
\hline 3 & 50 & 100 & -50 & 2500 \\
\hline 4 & 30 & 120 & -90 & 8100 \\
\hline 5 & 55 & 95 & -40 & 1600 \\
\hline \multirow[t]{2}{*}{6} & 80 & 70 & 10 & 100 \\
\hline & & & $\sum D=70$ & $\sum D^{2}=41300$ \\
\hline$(n=6)$ & $\left(\sum D\right)^{2}=4900$ & $* d f=5$ & $* t=0.318$ & $* c=2.571$ \\
\hline
\end{tabular}

\section{Discussion}

Eating disorder as major risk factor of aged related diseases according to Bonci C. M. et al. (2008) are less reported in preindustrial, non-westernized countries than in Western countries. Additionally, Arcelus, J. et al. (2014) reported that it occurs more commonly among those involved in activities that value thinness such as high-level athletics, modeling, and dancing. However, this study only emphasis on Anorexia Nervosa (AN), Bulimia Nervosa (BN) and Binge Eating Disorder (BED) regarding abstinence knowledge of athletes in decreasing unhealthy ageing with reference to physical and mental health, among athletes at Njala Campus. Standard deviation, mean and Dependent t-test among others, were used as statistical instruments in analyzing and proving of the results at level of significance $p<0.05$. Njala Campus Athletes knowledge about abstinence from eating disorders of Anorexia Nervosa (AN), Bulimia Nervosa (BN) and Binge Eating Disorder 


\section{Journal of Exercise Science \& Physiotherapy, Vol. 13, No. 1, 2017 \\ ISSN: 0973-2020 (Print) I2OR Impact Factor $=5.23$ UGC Approved [no.20489] ISSN: 2454-6089 \\ (Online)}

(BED) in decreasing unhealthy ageing with reference to physical and mental health was the objective of the survey. In the analyses, the responses from the participants were highly insignificant as holistically and negatively skewed [t-values of $0.237,0.452$ and 0.318 ] in their respective measured dependent variables in tables 5, 7 and 9, when tested at $p<0.05$. Abstinence from eating disorder of anorexia nervosa as skewed negatively in responses of Njala Campus Athletes, is a detrimental factor to health educators especially at Njala Campus tasked with the responsibility of educating athletes on their health risk behaviours such as anorexia nervosa as put forward by Strumia, R. (2009) that, anorexia nervosa and the associated malnutrition that results from self-imposed starvation, can cause complications in every major organ system in the body. Diet according to Whitnet, E. et al. (2011), is the most essential factor to work on in people with anorexia nervosa, and must be tailored to each person's needs. Food variety is important when establishing meal plans as well as foods that are higher in energy density. However, Marzola, E. et al. (2013), reported that people must consume adequate calories, starting slowly, and increasing at a measured pace.

As evidenced in the case of bulimia nervosa, a negatively skewed insignificant difference was also recorded as another detrimental factor and setback for health educators with respect to cognitive behaviours as reported by Hay, P. (2013) that, cognitive behavioural therapy is the primary treatment for bulimia nervosa. According to Barker, $P$. (2003), people with bulimia nervosa may also exercise to a point that excludes other activities. Bulimia nervosa as reported by Hay, P. J. et al. (2010), may affect up to $1 \%$ of young women and, after 10 years of diagnosis, half will recover fully, a third will recover partially, and 10-20\% will still have symptoms. However, Nauert, PhD, $R$. (2015),reported that, girls who are African American are 50 percent more likely than girls who are white to be bulimic and thatgirls from families in the lowest income bracket were 153 percent more likely to be bulimic than girls from the highest income bracket.

Again, binge eating disorder is another health risk factor behaviours under eating disorders that was skewed negatively from the responses given above by Njala Campus Athletes that has the propensity to posse psychological behavioural threat as reported by Iacovino, J. M. et al. (2012) that, psychological interventions such as psychotherapy and behavioural interventions are more effective than pharmacological interventions for the treatment of binge eating disorder. Mitchison, $D$. (2013) reported that, binge eating disorder has also been found to be similar among black women, white women, and white men. While some studies by Saguy, A. et al. (2014), have shown that binge eating disorder is more common among black women than among white women. Finally, as tabled in 4, 6 and 8 and figured in 1,2 and 3, the results however displayed a high negatively skewed holistic insignificant responses from Njala Campus Athletes knowledge bout abstinence from eating disorders of Anorexia Nervosa (AN), Bulimia Nervosa (BN) and Binge Eating Disorder (BED) in decreasing unhealthy ageing with reference to physical and mental health.

\section{Conclusion}

Knowledge bout abstinence from eating disorders of Anorexia Nervosa (AN), Bulimia Nervosa (BN) and Binge Eating Disorder (BED) in decreasing unhealthy ageing with reference to physical and mental health was the objective of the survey. With reference to the percentage scores, $t$-scores and mean scores, the results were skewed negatively with holistic values showing the fact that Njala Campus Athletes knowledge about abstinence from eating disorders of Anorexia Nervosa (AN), Bulimia Nervosa $(\mathrm{BN})$ and Binge Eating Disorder (BED) in decreasing unhealthy ageing with reference to physical and mental health was highly insignificant.

\section{Recommendation}

The following recommendations were put forward by the researchers: That training workshops be held readily for Njala Campus Athletes in the area of eating disorders of Anorexia Nervosa (AN), 


\section{Journal of Exercise Science \& Physiotherapy, Vol. 13, No. 1, 2017 \\ ISSN: 0973-2020 (Print) I2OR Impact Factor $=5.23$ UGC Approved [no.20489] ISSN: 2454-6089 \\ (Online)}

Bulimia Nervosa $(\mathrm{BN})$ and Binge Eating Disorder (BED) in decreasing unhealthy ageing with reference to physical and mental health. And that further survey should be carried out about effective monitoring and evaluation of more eating disorders among collegiate athletes with reference to Njala Campus Athletes in line with their eating habits to prevent and or to improve on their eating disorders.

Acknowledgement

The authors express sincere thanks and appreciation to all staff and students of Njala University, Njala Campus, whose immense co-operation rendered this study to fruition.

\section{References}

American Heart Association and American College of Sports Medicine (2007). Joint Position Statement: Exercise and acute cardiovascular events: placing the risks into perspective. Med. Sci. Sports Exerc: 39:886-897.

American Psychiatry Association (2013).Diagnostic and Statistical Manual of Mental Disorders $\left(5^{\text {th }}\right.$ Ed.) Arlington: American Psychiatric Publishing. pp. 329-354. ISBN 0890425558.

American Psychiatric Association (2013).Diagnostic and Statistical Manual of Mental Disorders (5 $^{\text {th }}$ Ed.). Arlington, V. A: American Psychiatric Publishing. pp. 345-349. ISBN 978-0-89042-5558.

American Psychiatric Publishing, (2013).Diagnostic and statistical manual of mental disorders: DSM5 ( $5^{\text {th }}$ Ed.). Washington: pp. 338-345. ISBN 9780890425558.

Anderson-Fye, E. P. and Becker, A. E. (2004). Sociocultural Aspects of Eating Disorders pp. 565-89 in Handbook of Eating Disorders and Obesity, J. Kevin (ed.). Thompson. Hoboken, NJ: John Wiley \& Sons.

Arcelus, J., Witcomb, G. L. and Mitchell, A. (2014). "Prevalence of eating disorders amongst dancers: a systemic review and meta-analysis." European eating disorders review: the journal of the Eating Disorders Association:22 (2): 92-101.

Artero, E.,España-Romero, V., Ortega, F., Jiménez-Pavón, D., Ruiz, J., Vicente-Rodríguez G., Bueno, M., Marcos, A., Gómez-Martínez, S., Urzanqui, A., González-Gross, M., Moreno, L., Gutiérrez, A. and Castillo, M. (2010).Health-related fitness in adolescents: underweight, and not only overweight, as an influencing factor. The AVENA study: Scand J Med Sci Spor: 20 (3): 418-427.

Attia, E. (2010). "Anorexia Nervosa: Current Status and Future Directions". Annual Review of Medicine:61 (1): 425-35.

Barker, P. (2003).Psychiatric and Mental Health Nursing: The Craft of Caring. Great Britain: Arnold. ISBN 0340810262.

Baum, A. and Auckland, N. Z (2006). "Eating Disorders in the Male Athlete" (PDF). Sports medicine:36 (1): 1-6.

Bebeley, S. J. (2016). Athletes' Knowledge about Preventing Sports Injuries like: Achilles Tendinitis Runner's Knee/Patellofemoral Pain Syndrome and Shin Splints, as Prime Prevention Strategies in Slowing Ageing Process. Journal of Exercise Science and Physiotherapy: 12 (1): 22-28.

Blagosklonny, M. V. (2009). Validation of anti-ageing drugs by treated diseases. Ageing 1 (3): 281-8.

Bonci, C. M., Bonci, L. J., Granger, L. R., Johnson, C. L., Malina, R. M., Milne, L. W., Ryan, R. R. and Vanderbunt, E. M. (2008). "National athletic trainers' association position statement: Preventing, detecting, and managing disordered eating in athletes". Journal of Athletic Training43 (1): 80-108.

Brewerton, T. (2014). "Binge Eating: Recognition, Diagnosis, and Treatment". Medscape Health Journal.

Bulik, C. M., Marcus, M. D., Zerwas, S., Levine, M. D. and La Via, M. (2012). "The changing "weightscape" of bulimia nervosa." The American Journal of Psychiatry:169 (10): 1031-6.

"Bulimia nervosa fact sheet" (2012). Office on Women's Health. 


\section{Journal of Exercise Science \& Physiotherapy, Vol. 13, No. 1, 2017 \\ ISSN: 0973-2020 (Print) I2OR Impact Factor $=5.23$ UGC Approved [no.20489] ISSN: 2454-6089 \\ (Online)}

D'Hont, E., Deforche, B., Bourdeaudhuij, I. and Lenoir, M. (2009). Relationship between motor skill and Body Mass Index in 5-to 10-year-old children: Adapt Phys Act Q: 26:21-37.

Donatelle, R. (2009). Promoting Healthy Behavior Change. Health: The basics: (pp. 4). 8th edition.

San Francisco, CA: Pearson Education, Inc.

Douglas, H. (2001). "Online Etymology Dictionary: bulimia". Online Etymology Dictionary.

Dumith, S., Ramires, V., Souza, M., Moraes, D., Petry, F., Oliveira, E., Ramires, S. andHallal, P. (2010).Overweight/Obesity and physical fitness among children and adolescents. J Phys Act Health: 7:641-648

Eating disorders and culture (2004).Harvard Mental Health Letter20 (9): 7.

Espi, F. F. (2013). Anorexia mirabilis: the practice of fasting by Saint Catherine of Siena in the late middle Ages. American Journal of Psychiatry:170 (4): 370-1.

Fairburn, and Christopher, (2013).Overcoming binge eating: the proven program to learn why you binge and how you can stop (Second ed.). New York: Guilford Publications: ISBN 1572305614.

Franko, D. L., Becker, A. E., Thomas, J. J., Herzog, D. B., Becker; Thomas; Herzog (2007). "Crossethnic differences in eating disorder symptoms and related distress" The International Journal of Eating Disorders:40 (2): 156-64.

Giannini, A. J. (1993). "A history of bulimia". In The Eating Disorders: (pp. 18-21) Springer New York.

Gull, Sir William Withey (1894). T. D. Acland, ed. Medical Papers. p. 309.

Gull, W. W. (1997). "Anorexia nervosa (apepsiahysterica, anorexia hysterica). 1868." Obesity research:5 (5): 498-502.

Hay, P. (2013). "A systematic review of evidence for psychological treatments in eating disorders: 2005-2012." The International Journal of Eating Disorders:46 (5): 462-9.

Hay, P. J. and Claudino, A. M. (2010). "Bulimia nervosa". Clinical Evidence 2010: 1009.

Iacovino, J. M., Gredysa, D. M., Altman, M. and Wilfley, D. E. (2012). "Psychological treatments for binge eating disorder" Curr Psychiatry Rep:14 (4): 432-46.

Joint Committee on Terminology (2001). "Report of the 2000 Joint Committee on Health Education and Promotion Terminology". American Journal of Health Education:32 (2): 89-103.

Kirkwood, T. and Austad, S. (2000). Why do we age? Journal of nature 408: 233-238,

Lennox, A., Pienaar, A. and Wilders, C. (2008).Physical fitness and the physical activity status of 15year-old adolescents in a semi-urban community: $S$ Afr $J$ Res Sport Phys Educ Recreation. (2008) 30(1): 59-73

Maffuli, N., Chan, K., Macdonak, R., Malina, R.M. and Parker, A.W. (2003).Sports medicine for specific age group and abilities. Elservier health services Churchill Livingstone.

Marzola, E., Nasser, J. A., Hashim, S. A., Shih, P. A. and Kaye, W. H. (2013). "Nutritional rehabilitation in anorexia nervosa: review of the literature and implications for treatment". BMC Psychiatry13 (1): 290.

McBride, H. (2012). "Study Reveals Stunning Prevalence of Bulimia among African-American Girls". Archived from the original (2012).

McKenzie, J., Neiger, B. and Thackeray, R. (2009). Health Education can also be seen as preventive medicine (Marcus 2012). Health Education and Health Promotion. Planning, Implementing, \& Evaluating Health Promotion Programs: (pp. 3-4). 5th edition. San Francisco, CA: Pearson Education, Inc.

Miller, K. K. (2013). "Endocrine effects of anorexia nervosa". Endocrinol. Metab. Clinic North America: 42 (3): 515-28.

Mitchison, D. (2013). "Sex differences in health-related quality of life impairment associated with eating disorder features: A general population study". International Journal of Eating Disotders:46: 375-380.

Nattiv, A., \& Puffer, J.C. (1991). Lifestyles and health risks of collegiate athletes.The Journal of Family Practice: 33 (6), 585-590.

Nauert, PhD, R. (2015). Black Girls at Risk for Bulimia. Psych Central. Retrieved from 


\section{Journal of Exercise Science \& Physiotherapy, Vol. 13, No. 1, 2017 \\ ISSN: 0973-2020 (Print) I2OR Impact Factor $=5.23 \quad$ UGC Approved [no.20489] ISSN: 2454-6089 \\ (Online)}

http://psychcentral.com/news/2009/03/19/black-girls-at-risk-for-bulimia/4835.html

Pearce, J. M. (2004). "Richard Morton: Origins of Anorexia nervosa". European Neurology: 52 (4): $191-192$.

Rikani, A. A., Choudhry, Z., Choudhry, A. M., Ikram, H., Asghar, M. W., Kajal, D., Waheed, A. and Mobassarah, N. J. (2013). "A critique of the literature on etiology of eating disorders.". Annals of Neurosciences:20 (4): 157-61.

Russell, G. (1997). The history of bulimia nervosa. D. Garner \& P. Garfinkel (Eds.), Handbook of Treatment for Eating Disorders ( $2^{\text {nd }}$ Ed., pp. 11-24). New York, NY: The Guilford Press.

Saguy, A. and Gruys, K. (2014). "Morality and Health: News Media Constructions of Overweight and Eating Disorders" (PDF). UCLA.

Sari Fine Shepphird (2009).100 Questions \& Answers about Anorexia Nervosa: Jones \& Bartlett Learning. p. xvi. ISBN 9781449630799.

Smink, F. R., van Hoeken, D. and Hoek, H. W. (2012). "Epidemiology of eating disorders: incidence, prevalence and mortality rates." Current Psychiatry Reports:14 (4): 406-14.

Strumia, R. (2009). "Skin signs in anorexia nervosa". Dermatoendocrinol:1 (5): 268-70.

Surgenor, L. J. and Maguire, S. (2013). "Assessment of anorexia nervosa: an overview of universal issues and contextual challenges". Journal of Eating Disorders:1 (1): 29.

Taanila, H., Hemminki, A., Suni, J., Pihlajamäki, H. andParkkari, J. (2011).Low physical fitness is a strong predictor of health problems among young men: a follow-up study of 1411 male conscripts. BMC Public Health; 11: 590.

Tölgyes, T. and Nemessury, J. (2004). "Epidemiological studies on adverse dieting behaviours and eating disorders among young people in Hungary". Social Psychiatry and Psychiatric Epidemiology:39 (8): 647-54.

Walsh, J. M., Wheat, M. E., Freund, K. and Wheat, F. (2000)."Detection, evaluation, and treatment of eating disorders". Journal of General Internal Medicine: 15 (8): 577-90.

Weiss, S. (1995). A comparison of maladaptive behaviors of athletes and non-athletes. The Journal of Psychology: 133(3), 315-322.

Westerburg, D. P. and Waitz, M. (2013)."Binge-eating disorder". Osteopathic Family Physician:5 (6): 230-33.

What are Eating Disorders?NIMH (2015).

Whitnet, E. and Rolfes, S. R. (2011).Understanding Nutrition. United States: Wadsworth Cengage Learning. p. 255. ISBN 1-133-58752-6.

World Health Organization (1998). List of Basic Terms. Health Promotion Glossary: (pp. 4). Retrieved (2009).

World Health Organization (2002).Reducing risks, promoting healthy life. World Health Report 2002 Geneva, Switzerland. WHO Press

World Health Organization's (2010). Global recommendations on: Physical Activity for Health. Geneva: World Health Organization.

Conflict of Interest: None declared 